\title{
Synthesiology Workshop at the Annual Meeting of the Japan Society for Science Policy and Research Management (JSSPRM)
}

\section{Synthesiology through knowledge integration to innovation}

[Translation from Synthesiology, Vol.5, No.1, p.62-68 (2012)]

This is a report of the synthesiology workshop "Synthesiology through knowledge integration to innovation" at the Annual Conference of the Japan Society for Science Policy and Research Management, held at the Tokiwa Campus, Yamaguchi University in October 2011.

Synthesiology Editorial Board

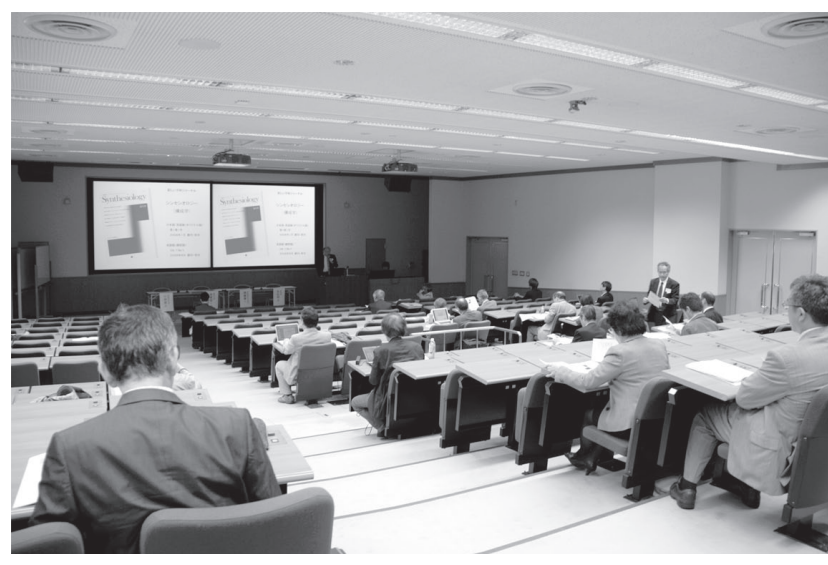

[Opening Address]

Naoto Kobayashi (Vice Editor-in-Chief, Synthesiology; Waseda University)

What can we, or those of us involved in "academics" and "research," do in the face of the difficulties that stand before us including the global economic crisis, the high yen rate, the floods in Thailand, the decelerating growth of emerging countries, the recovery from

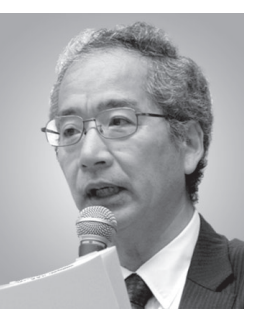
the enormous earthquake, and the massive national deficit? I think we must utilize the products of R\&D in society and create and accelerate innovations.

Synthesiology aims to practice the science of synthesis and accelerate innovation, by integrating the scientific findings and technologies. The Japan Society for Science Policy and Research Management studies the proposal, planning, management, intellectual property, and technology management to enable the utilization of science and technology toward innovations. However, looking at the real world, even if an excellent research result or technology is created, that alone will not lead directly to innovation or be accepted into society.

Then what must be done to promote innovation? This workshop is a place to discuss the "methodology to link synthetic knowledge to innovation," and it is held jointly by Japan Society for Science Policy and Research Management

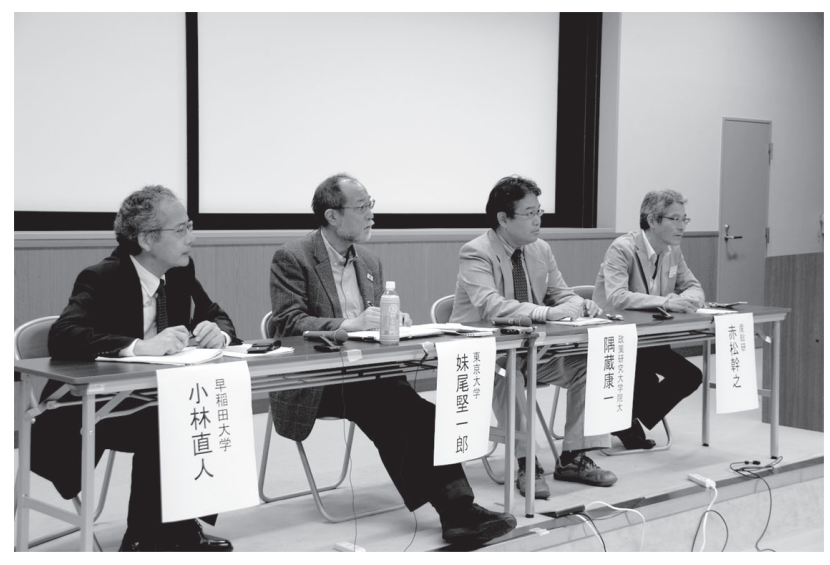

(JSSPRM) and AIST. In this workshop, the methodology of synthesis science will be discussed. We also hope to step into the innovation theory, give specific examples of methods for promoting innovation, and deepen mutual understanding.

As the keynote address, we shall hear from Dr. Ono of AIST on the "Methodology for the establishment of synthetic knowledge." Then, Prof. Ken Senoh of The University of Tokyo will give a special lecture, "Innovation and synthesiology - How knowledge creation and restructuring can be useful in converting the social value and strengthening the industrial competitiveness." Finally, Prof. Senoh, Dr. Sumikura of the National Graduate Institute for Policy Studies, and Dr. Akamatsu of AIST will join us in the panel discussion entitled "From knowledge integration to innovation creation."

\section{[Keynote Lecture] Methodology for the establishment of synthetic knowledge}

Akira Ono (Editor-in-Chief, Synthesiology; AIST)

Much time is needed for the basic scientific research to get out into the real society, and many scientific results become lost in the process. How do we overcome this "valley of death" or "period of nightmare" of research? I wish to establish the methodology through Synthesiology.

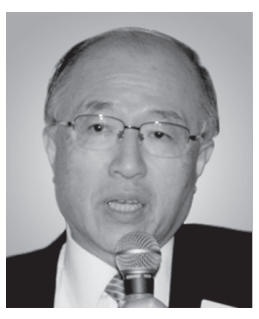

\&11 
First of all, in scientific research, one selects a discipline such as physics, biology, or electricity. Next, using the method of analysis, one classifies various phenomena into hierarchies, break them down into knowledge elements, and finally organize them systematically to understand a certain aspect of nature. Ever since the birth of science in the 17th century, science has been developed mainly by reductionism and analytic methods. On the other hand, there is the activity of creating a purposeful artifact that does not originally exist in nature. Using knowledge elements obtained in various disciplines, materials, parts, components, systems, services, and environments are created according to scenarios. Here, the processes of synthesis from and integration of knowledge

\section{Comparison of analytic research and synthetic research}

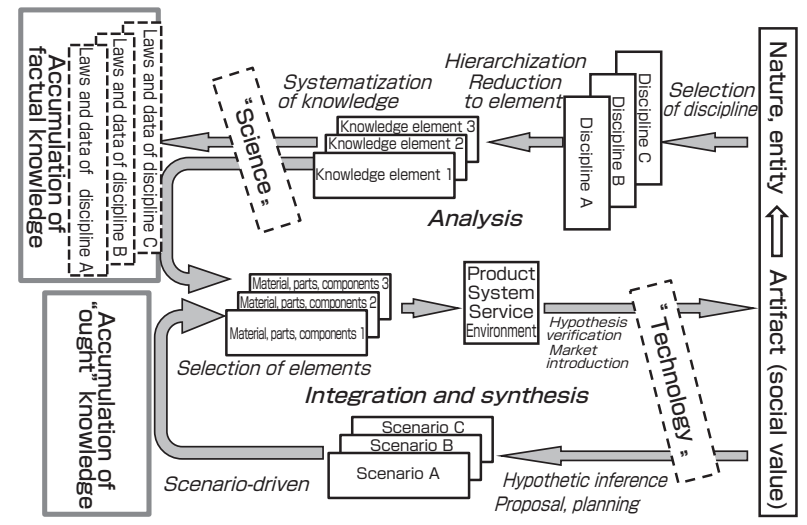

elements are important. The former may be defined as "science" and latter as "technology." When an artifact created is recognized as an "entity," that itself becomes the subject of analysis, and results of these analyses are used for technology again. I believe this is the interaction of "science" and "technology." This is what is called kogaku (engineering) in Japanese. However currently, there is a trend where engineering itself is also being broken down into disciplines.

Let us compare analytical research and synthetic research. In terms of methodology, the analytical research is by analysis and breakdown, while synthetic research is by synthesis and integration. The former normally is done in a single discipline, while the latter is done across multiple disciplines. The major difference between the two researches is whether there is a unique solution. Under the belief that there is a unique solution with factual knowledge, the analytical research never stops until a unique solution is attained, and the research is completed when this point is reached. In the synthetic research, there can be multiple, equivalent solutions. Although there may be varying degrees of excellence among the solutions, the nature of synthetic research is very distinct from that of analytic one in the point that there may be multiple, equivalent solutions. When evaluating the analytical research, the peer reviewing is done by experts, because in a finely specialized discipline, only the experts of that particular discipline can determine whether a conclusion is a unique solution. However, in the synthetic research, the evaluation should be done by people who use the research results or those who gain benefit from them. I think the reviewing of synthetic research may be a merit review done by non-experts.

Issues of the present society including the environmental issues are extremely complex. Although the "science of synthesis" is needed along with the "science of analysis," the "science of synthesis" has not been sufficiently formulated, and the knowledge of what ought to be done are only accumulated and enclosed within individual researchers or groups. I do not want such knowledge to be lost. It must be accumulated as social assets, and made available to the public. Also, I want the researchers who are capable of the "science of synthesis" to be highlighted more, to have their proper place in society, and to be more active in promoting innovation. One of our innovation issues is "how to form the strong link between basic research and the real world." It is necessary to establish the methodology of the "science of synthesis" and to solve the issues of the present society through its practice. To do so, it is important to develop a formulation of original research papers to describe the "science of synthesis," and that is the reason we launched the new journal Synthesiology.

The characteristic of Synthesiology is that it offers the shift from a narrow discipline to wide disciplines, from the novelty of knowledge to its usability, and from the peer review to merit review. It also highlights the researchers capable of innovation. Another characteristic of the journal is that the discussions between the authors and reviewers are placed at the end of the papers with disclosure of reviewers' names. In ordinary academic journals, reviews are done anonymously from the perspective of neutrality and fairness, but we took the stance of developing the paper formulation with the cooperation of the authors and reviewers, as well as the readers, and decided to present the dialog between the authors and reviewers. What we learned from this is that because the names are disclosed, the reviewers cannot give biased opinions and comments, and due to this autonomous feedback and the obligation to be neutral and fair, they give excellent reviews, and the discussions with the authors are now very interesting. Some readers even read the discussions between the authors and reviewers before they read the actual papers.

In the past four years, we received various positive comments from many readers. Some authors said, "I was able to write things that could not be written in conventional academic journals." Some readers said, "It is interesting because I can understand clearly researches of other fields," and some industry people commented, 
"This is useful information because we can understand the researches of many fields."

To solve the issues of the present society, it is important to establish the methodology of the "science of synthesis" and to practice it. I believe innovation can be accelerated through the "science of synthesis."

\section{[Special Lecture] Innovation and synthesiology - How knowledge creation and restructuring can be useful in converting the social values and strengthening the industrial competitiveness- \\ Ken Senoh(The Industry Academia Collaboration} Initiative NPO; Hitotsubashi University [The University of Tokyo on the day of this workshop])

First, I would like to discuss "synthesiology seen from two systems theories' view," then "synthesiology seen from innovation studies," and finally "how knowledge creation and restructuring contribute to converting social values and strengthening industrial competitiveness"

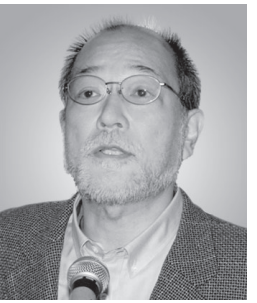

I shall review the systems theories. The systemic systems theory based on the phenomenological interpretation is, in that sense, British rather than American. When we approach a subject, there are four ways: 1) daily life approach, 2) scientific approach, 3) hard systems approach, and 4) soft systems approach. In daily life, we "wait and see" through our "preconception," or the framework based on various existing worldviews or Weltanschauungen and unexamined assumptions. To this, we add the approach based on "scientific thinking." This is represented by the three Rs: analysis based on "reductionism," adaptation to the world with "repeatability," and the factual expression of the result or, in Popper's term, to enunciate by "refutation." This can be called scientific knowledge when it is synthesized as "knowledge." The success of this methodology is apparent as evidenced from the world of science in the 19th and 20th century. However, we reached the limit of it. Why? It's because reductionism cannot get the knowledge of "wholeness" or "systemicity." The practical, managerial, or political actions is not repeatable due to human learning. Hence, the general systems theory such as of Bertalanffy appeared. The systems theory focuses on "relationships of elements," rather than looking at certain parts in a reductionistic manner. The systems theory was led by the engineering approach that assumed that the existing world was composed of "systems," and therefore it could be approached systematically. With the influence of the World War II, this hard systems concept dominated the scene. This methodology developed as system engineering (SE), operational research (OR), system analysis (SA), and management science (MS). Meanwhile, the soft systems concept developed in the 1980s mainly in England. Unlike the hard systems concept where the hypothesis verification is done assuming that the "world is composed of a set of systems," this is a paradigm that takes the approach of systemic exploratory learning assuming that "although the world can be seen as a system, the world is unknown." While the hard systems view is based on logical positivism that involves the hypothesis verification through ontological statement, the soft systems view is based on phenomenological and interpretationism centering on the exploratory learning through epistemological statement. It is characterized particularly by the social semantics and conceptualism for understanding a human action can be regarded as various systems.

What would happen when Synthesiology is seen from this perspective? I think there are two perspectives. First, there can be a paradigm of rationalization and emergence against the thinking of whether synthesiology engages in analysis or synthesis. Second, there are the three aspects of "logy." Does synthesiology seek statements by ontology, epistemology, or methodology? I think there are all three aspects to synthesiology.

Since we place emphasis on "emergence," the important concept is "correlation." In "correlation," the social phenomena are interpreted and recognized as emergences, but there is a need of the methodology for practice that enables the emergence of new social phenomena. I think there are the following six ways: 1) to replace the individual that composes the system that enables emergence, 2) to change the correlationship of the individual that composes the system, 3) to cause a new combination by design, 4) to cause a new combination by induction, 5) to discover and nurture new combinations through place and opportunity, and 6) to practice exploratory learning that causes emergence by directly being involved in the place and opportunity.

Next is "synthesiology seen from innovation."

When talking about innovation, I stress that "growth" and "development" should be separated. Growth is a quantitative expansion of / in the same model, while development means the non-successive transfer to a new model. What promotes growth is the improvement by polishing the current state, while innovation means the new creation of a model. I am saddened that the Nihon Keizai Shimbun still translates "innovation" as gijutsu kakushin (technological renewal), but no matter how much improvement is done, it is only a part of innovation. Innovation is a creation of social / industrial new value(s), so it does not necessary start with technology invention. Or invention needs to have further parts: conversion and diffusion. Innovation does not last long. It is impossible to win the industrial competition without ceaseless effort in innovation. In my innovation theory in terms of industrial competition, the improvement model and the new creation model must be clearly separated 
ideologically. In doing so, it is extremely important to combine the two models. In a company, it is essential to internalize the Christensen-style innovation dilemma within a company. In Canon's research center, they engage in research to crush Canon itself, and at Toyota's research center, they do research to beat Toyota itself. Unless they do that, the companies will be crushed by external innovation. If the companies do not want to be crushed by innovation, there is no other way but to engage in self-innovation. We have entered such a world.

Then how can synthesiology support innovation? Before going into that, I would like to check two points. First, innovation is not invention itself. I do not understand the phrase "innovation of science and technology." That is because something that just newly creates some social value is not an innovation unless it is diffused and becomes rooted in society. If something merely creates technological value, then it is an invention. That is one of the issues that I shall raise. Second, even if the current model is improved or refined, it will not become an innovation. It is necessary to separate the improvement of the existing model and the innovation that is the creation of the new model. Even if the record technology is advanced, it will not surpass the $\mathrm{CD}$, and even if the CD technology is advanced as far as possible, ultimately the world of iPod will take over. In this case, how do we create, diffuse, and make the new value adhere? I think synthesizing is one of the methodologies in the sense of "integration" or "synthesis," along with creation, generation, and producing. But is this all?

Finally, I shall discuss "how knowledge creation and restructuring contribute in converting the social values and strengthening the industrial competitiveness."

The methodology of innovation includes the "technological driven innovation" type on which the JSSPRM places emphasis, but there is also the "business driven innovation" type where a business concept or a value design is the starting point and the technology is utilized by the initiative of the design or the concept. It can be concept driven or design driven. For example, "iPod" is an example that started from product planning that creates new social values. The "Asahiyama Zoo" is an example of starting from the concepts or meaning and then changing the thing and action. The popularity of the zoo increased because it shifted from the concept of "exhibit of animal form/ outlook" to the "exhibit of animal behavior," and the design of the zoo was changed entirely. Design driven includes the "smart design" where the border between the every day and the extraordinary is crossed, for example, using sundry goods as emergency items. I am currently starting that movement with business companies. I call this "the shift from 'or' relation to 'and' relation." There are also concepts of universal design and eco design, but these are also styles where the starting point is an innovative concept from which the technology is induced or exisiting technologies are gathering.

Then, there is a "business concept / design driven innovation" style. Shifting from the age when manufactured articles equaled commercial products, now is the age where software and useware come into hardware. The iPod promotes the innovative formation of new value along with the service called the iTunes store. I have stated that while Walkman is a player, iPod is a fusion of the media, player, and storage, and moreover, it is a complex value form joined with the service called the iTunes store. All the business models are moving in this direction. The value formation by the synergetic hierarchization of the product and service is innovation of the product and business model or architecture.

Up to the 20th century, something could be produced by doing a survey and studying the needs. Some people translate "needs" as "wants" or "requests," but people like me and those in marketing translate the term as "shortage," "absence," or "deficiency." It is no longer an age where the subject of the survey is to fill in the deficiency. In the age where multiple, vertically-integrated companies could work hard and succeed by independence and doing everything by themselves, technology was linked directly to innovation. However, such methodology is not valid today, in the age of "innovation by internationally inclined division of labor" through the development of business models and intellectual property management, as well as standardization in a wide sense. Like in the age when the company became a leader if it was technologically excellent, will business excel if technology excels now? In the age of G7, the market was composed of advanced countries with a billion people. In the age of G20 plus, we must face the world of over 4 billion people. In such a world, the technology changes completely according to product architecture, business model, and industrial ecosystems. This may be like picking a fight with those of you working on technological policy. In fact, I am picking a fight. I think people should turn their eyes to the new cardinal rule of industry, that once the industrial ecosystem is made, one will not be able to survive even if excellent elemental technology is developed.

Here is the conclusion. The R\&D policy that assumes technological excellence equals industrial excellence is no longer valid. Or, the policy that merely assumes that all industrial competitiveness originates from technology is no longer valid. These are the basic models when the concept of intellectual property nation was established in 2002. Of course, it is the main road and so it is important, but we must see the reality that the innovations of the world are moving along the road of business domination. We must think that each wheel is important. How would synthesiology change the world in what ways? What kind of discussions should we engage in? I think those are the things we must seek. At any 
rate, I expect a lot from the development of synthesiology.

\section{[Topic contribution] Koichi Sumikura (National Graduate Institute for Policy Studies) \\ Inspired by the lectures, I would like to contribute some topics in relation to intellectual property.}

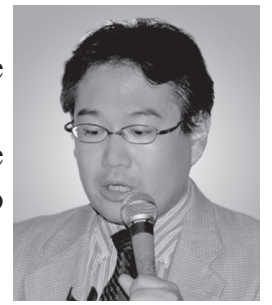

One of the points of Synthesiology is to "achieve the goal through the selection and integration of the elements." The right to intellectual property has the original function of exercising the individual right while maintaining exclusivity, or in other words, the function to block and slow down other people's R\&D. However the intellectual properties in the future may enter the age of synthesis. Various intellectual properties including patents and know-how are selected, integrated, pooled, and packaged to promote their distribution. This will encourage $R \& D$, as the innovations will be promoted since people can easily access the accumulated knowledge. I would like to introduce a case study.

I considered two patterns of cooperative management of intellectual property. One is the pattern where " $R \& D s$ are conducted individually at each institute while the management of intellectual property is done jointly."

This includes the patent pool that assumes the conclusion of a license contract with a monetary agreement, and the commons that assume the use free of charge. It is important to determine which elements to select, what package to make, and how these are diffused.

A famous example of a patent pool is MPEG-2. It is licensed as a package by creating a patent portfolio, and it is very successful as a business. In the field of agriculture, the Golden Rice contains high quantity of vitamin A and is expected to improve the nutrition of the people of developing countries. In this case, by packaging a product with over 70 patents in the United States alone and the need to sign six material transfer contracts, the time and cost of negotiating with individual right holders are avoided to promote the diffusion of the technology. Another example is GlaxoSmithKline plc. While this is a CSR activity by a company, an attempt is made to construct a patent pool for neglected topical diseases to provide it at low cost, and other companies are asked to participate. There is also a similar movement in the agricultural field for developing software by open source. The Cambia of Australia asks the BiOS licensees to allow free use of any improved inventions generated. On the other hand, for example, there is the commons that collect the data for drug toxicity with the concept of preventing dual investment on the toxicity tests, and the patents of specific fields are aggregated and packaged to be used free of charge, as in the eco patent commons.

\begin{tabular}{|l|}
\hline $\begin{array}{l}\text { Intellectual property rights } \\
\text { enter the age of synthesis }\end{array}$ \\
- Selection and integration of element $\Rightarrow$ Achievement of goal \\
- Intellectual property rights: \\
Maintenance of exclusive rights by execution of individual rights \\
(= Blocking and delay of R\&D) \\
$\downarrow$ \\
Pooling and distribution promotion through selection \\
/integration of intellectual knowledge \\
(= Promotion of R\&D, promotion of access to knowledge)
\end{tabular}

Second is that the "R\&D is done jointly by multiple institutes and at the same time the management of intellectual property is done under a certain rule." The SC4SM (Stem Cells for Safer Medicines) is a British government-private sector consortium that enables the use of stem cells such as iPS cells in the drug toxicity tests. The government institutes and major pharmaceutical companies participate to develop the mechanism and to manage the developed patents.

Finally, I would like to touch upon the development of new technology for "enabling both the reduction of energy consumption and economic vitalization." In the situation after the earthquake, the economic vitalization must not be stalled while it is necessary to reduce the energy consumption. To do so, it is necessary to create a mechanism for widely gathering demands, to develop the necessary elements, to conduct R\&D to combine such elements, and to have this new technology spread throughout society.

As one specific plan, a bottom-up type website like Wikipedia where anyone can write can be set up to gather the demands. For the combination and development of necessary elements, the technology needed immediately is determined by committees of experts, and the R\&D is promoted by preferential tax treatment or reduction/exemption of patent fees. Then, to diffuse the implemented product, the companies that use such products are given preferential tax breaks. Such mechanism can be considered. I mention these as the materials for discussion pertaining to the handling of intellectual property rights and the possibility that reduction/ exemption of patent fees may help promote R\&D.

Motoyuki Akamatsu (Senior Editor, Synthesiology; AIST)

The general process by which R\&D was used in the market until now was that the company people found and used the elemental technology research results. Synthesiology aims to establish a methodology that allows the product

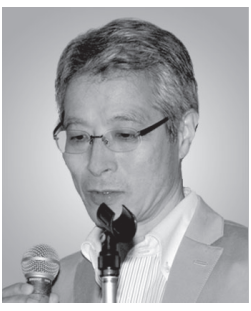
realization in society from the researchers' side. We analyzed and categorized about 70 Synthesiology papers on how the researches entered society and what scenarios and processes were taken. I would like to present some examples. 
There is the group of "cases where the demand is clarified in society." In the research where the performance of the hard disk was increased using spintronics, the companies grabbed this technology when it was shown that the performance increased greatly. Moreover, when the researcher contributed in the development of the production system, the companies were able to deploy the technology more readily. Also, there were cases where the use of technology was established as a social structure, as in the case of the traceability of measurement standard.

On the other hand, there are "cases where the social demand is not clarified." In this case, the process of (1) "trial use" is important. The researcher created a nanotube with organic material, thought that the potential for its usage is infinite, and wanted to see how it could be used by providing samples. One of the points here was to provide the sample while showing that the product could be mass-produced in the manufacturing process. Another example is Aimulet, the powerless portable information device used at the Aichi Expo to explain the exhibits. By using the product at exhibitions and events, the demands can be excavated and the technological development is conducted by taking in feedback for improvements.

There is also the method of (2) "demonstrating by making the product." The actual product is made to specifically present what kind of performance the product is capable of. The emission wavelength of the iodine stabilized $\mathrm{He}-\mathrm{Ne}$ laser that is used as the national standard of lengths in many countries was determined by the mechanical length of the laser resonator. The general-use elemental technologies were integrated adeptly to create a compact standard that fit on a desk, and this was used to demonstrate the fact that "it could be made this small." Also, real time all-in-focus microscope was realized as a product by demonstrating the impact that the image could be focused for objects with varying heights.

\section{Scenario for introducing the outcome of R\&D to society}

\begin{tabular}{|c|c|}
\hline $\begin{array}{l}\text { In cases the demand } \\
\text { is clarified by industry }\end{array}$ & $\begin{array}{l}\text { - Construction of traceability system for measurement standard } \\
\text { - Development of production technology that } \\
\text { matches the new technology }\end{array}$ \\
\hline \multirow{5}{*}{$\begin{array}{l}\text { In cases the demand } \\
\text { is not clarified by industry }\end{array}$} & $\begin{array}{l}\text { Display elemental technology and provide samples } \\
\text { - Present impact of new technology by demonstrating } \\
\text { the function using the sample } \\
\text { - Extract technological problem and research items } \\
\text { through feedback obtained from sample trial }\end{array}$ \\
\hline & Provision of the prototype for wide trial opportunity \\
\hline & $\begin{array}{l}\text { - Rent out prototypes to target users, and extract } \\
\text { problems and necessary functions from open prototype } \\
\text { - Express impact of realized function by creating } \\
\text { the product }\end{array}$ \\
\hline & Promote technological introduction to the stakeholder \\
\hline & $\begin{array}{l}\text { - Take time to obtain understanding of the value } \\
\text { of new technology } \\
\text { - Promote understanding by seeking problems } \\
\text { jointly with the people on site }\end{array}$ \\
\hline $\begin{array}{l}\text { Establishment and } \\
\text { expansion of industry }\end{array}$ & $\begin{array}{l}\text { - Add use value of the product through sensitivity-based } \\
\text { leading user } \\
\text { - Collaboration with different businesses, sectors and competing } \\
\text { companies and standardization with competing companies, } \\
\text { construction of joint relationship }\end{array}$ \\
\hline
\end{tabular}

Then there is (3) "the demand is understood, but there is hesitation." There is understanding for the necessity and importance of the technology, but people are hesitant to actually work on it due to intellectual property issues. In such a case, the researcher must wait for the company's understanding, or jump right into their arms. In the case of ultraviolet protective cosmetics, the product was made but the negotiations stalled due to intellectual property issues. Therefore, it was put on hold for a while, and after two to three years of adjustment, the product was finally realized. In the group that engaged in the activity to increase the reliability of the information system, the researchers actually entered the field to have the people understand the value of the technology.

Finally, there is the group of "cases where the product is created and it must be spread in society." The contribution of diverse stakeholders will be the point here. In the process of the diffusion of the IH cooking device into homes, an important role was played by a certain cooking instructor, a sensitivity based leading user. Also, car navigation is an integration of various technologies from micro to macro, from elemental technology to the whole social system. The car navigation was spread by the coordination of the entire industrial system and the people involved considering their roles. In this case, particularly important was the fact that the people of the companies of each layer shared the dream of "spreading the car navigation."

These are summaries of some case studies, and I hope they serve as material for the following discussion.

\section{Panel discussion: From knowledge integration to innovation creation Kobayashi}

I would like to receive questions and comments from the audience on the presentations of the methodology for linking the "synthesized knowledge" to innovation.

\section{Audience}

The 4th Science and Technology Basic Plan decided upon the direction "from science and technology policy to science, technology innovation policy," but the situation seems to be that no one knows what we are supposed to do. In this time of crisis, isn't this a chance to change the framework of concept? I would like to hear radical remarks from Prof. Senoh and Dr. Sumikura.

\section{Senoh}

I feel that the "perceived rate of innovation" is extremely slow only in Japan. The problem of valley of death exists so it must be solved. However, looking at the American and European business models, they devise a model so the valley of death will not occur. Rather than solving the problem, they try to prevent the problem from happening. I think we 
must learn from this. If the market grows rapidly without putting in the investment funds, the investment to R\&D can be recovered very quickly. I am wondering why Japan is unable to create a model of win-win relationship with the emerging countries in this style.

\section{Sumikura}

As a method for gathering the technology needed in society, there is, for example, a map website where people with GPS cellphones walk or drive, the route taken is displayed like a map, and other people can follow the route. This indicates the possibility of truly bottom-up manufacturing, and I think this method can be utilized effectively.

\section{Senoh}

That map can be considered user-driven rather than vendor-driven. Instead of the concept that the proposal for innovation is done by the vendor, we must bring out the power of the user-driven innovation. In the crisis situation today, what is talked about is social innovation. I think the social innovation is to "do social things by social participants in a social manner." The sense of stagnation today in the living space and social space cannot be overcome unless the value of the whole society is changed. Now, the field of social business is emerging. I would like to focus on the fact that the world in which various things are innovated by linking socially in the same space is starting to take off.

\section{Audience}

As the precursor of the JSSPRM, the 2nd Department of Basic Science was created 30 years ago in the University of Tokyo, and it was about doing synthesis and doing something practical. What do you think about the relationship between Synthesiology and discipline, and the mechanism for actualizing them?

\section{Akamatsu \\ Synthesiology aims to seek some sort of methodology that transcends the existing disciplines, by gathering case studies. For example, the categorizations include the strategic selection, breakthrough, and aufheben types. The good thing about Synthesiology is that it regards all fields as its subjects. One can understand even if it is not one's own field of specialty, and that is because there is a common thread in the "way of thinking of the researcher." We can discuss and understand mutually from the perspective of synthesis. I think that will be one of the powers that enable the construction of the discipline to link the disciplines.}

\section{Senoh}

In terms of disciplinary, I think there are six methods for developing a new discipline: apical / advanced knowledge, interdisciplinary knowledge, niche / interstitial knowledge, fused knowledge, cross-disciplinary knowledge, and meta level / superior knowledge. Also, I question whether the cutting-edge discipline will be of hypothesis verification, and I think it will be of exploratory learning. When looking at Synthesiology from the sideline and wondering where it will go, I feel that there can be developments of epistemological discipline and methodological discipline, rather than ontological discipline. If that is its orientation, I think synthesiology has huge potential to bring about a wonderful discipline, and it is exciting.

\section{Ono}

Thank you for your very encouraging comment. The term kagaku (science) in Japanese has the meaning of "individual branches of knowledge." I am thinking that a definitive discipline will not be made in synthesiology, and now we emphasize the three forms of methodology that can be used commonly and cross-sectionally for each discipline, or for its fusion. Yet, I would like to investigate further the forms Prof. Senoh suggested.

\section{Kobayashi}

Pertaining to "how to discuss the policy that leads to innovation," you talked about "innovation is done by user driven rather than vendor driven" and "Japan cannot keep up with the speed of the world." How about "how to plan and lead to the policy?"

\section{Akamatsu}

I think one feels something only after picking up that object in one's hand. Since the thing and system that became an entity is very powerful, one way is to set up the process of developing it by receiving feedback. Until now, the thing could not be created without the solid build-up of hardware, but I think some assumed form can be made at a very early stage by using simulations.

\section{Sumikura}

I have suggested that a bottom-up system is necessary as a mechanism to collect the demands, but of course, there are various routes. There are cases where basic research done without considering any particular demand may link to a demand. Therefore, we need a matching mechanism to pick out such researches and put them into necessary places, and it's also necessary to train connoisseurs for their interaction.

\section{Senoh}

Everyone started to develop "a way of knowledge for how to use knowledge." That's the point. I talk about the "knowledge to utilize knowledge," and what Japan is lacking is not the development of knowledge itself, but the development of knowledge to utilize knowledge. I would like to consider synthesiology as an attempt to develop the knowledge to utilize knowledge. 


\section{Akamatsu}

It is not factual knowledge, but the "knowledge of what ought to be." I think that is the main target.

\section{Senoh}

I think it is great that you stepped in that direction. One is that temporal and spatial transformations are occurring in R\&D. It must be global first rather than domestic leading such as in something done locally being sent out globally. Talking about the time issue, is it still okay to consider shortterm as one to three years, mid-term as five years, and longterm as 10 years? Defining the short-term of innovation as the period of polishing the existing model, long-term as the period of diffusion and fixing of the next-generation model, and mid-term as the period of transition from the old to new model, there is a distinct difference temporally between the world of bio and the world of IT.

Another point is the gap between the policy and the industrial trend, and I suggest retuning this separation. I hope that the methodology of this retuning will be one of the targets developed in Synthesiology.

\section{Kobayashi}

We would like today's discussions to be developed further. We have gained much new insight today, and we hope the audience was able to find some new direction. I shall close the panel discussion here. Thank you very much. 